\title{
PENGARUH WILLIAM'S FLEXION EXERCISE DENGAN LANTUNAN AYAT SUCI AL QUR'AN TERHADAPSKALA NYERI HAID (DISMENOREA) PADA REMAJA PUTRI PANTI ASUHAN DARUL ULUM YOGYAKARTA
}

\section{THE EFFECT OF WILLIAM 'S FLEXION EXERCISE WITH THE QUR'ANIC VERSES ON THE SCALE OF MENSTRUAL PAIN (DISMENOREA) IN ADOLESCENT AT THE DARUL ULUM ORPHANAGE YOGYAKARTA}

\author{
Dwi Astuti' ${ }^{1}$ Dian Nur Adkhana ${ }^{2}$. \\ ${ }^{1}$ Mahasiswa Program Studi Ilmu Keperawatan STIKes Surya Global Yogyakarta. ${ }^{2}$ Dosen \\ Keperawatan Stikes Surya Global Yogyakarta.
}

\begin{abstract}
ABSTRAK
Nyeri Haid (dismenorea) adalah nyeri yang terjadi sebelum atau selama menstruasi. Dismenorea dapat menggangu aktivitas remaja dan secara tidak langsung dapat mengganggu kualitas hidupnya apabila tidak ditangani. Tujuan penelitian ini adalah untuk mengetahui pengaruh William's Flexion Exercise dan Lantunan Ayat Suci Al Qur'an terhadap Skala Nyeri Haid (Dismenorea) di Panti Asuhan Darul Ulum Yogyakarta. Jenis penelitian ini menggunakan desain penelitian Pra - Experimental dengan one-group pra-post test design. Teknik pengambilan sampel menggunakan purposive sampling dengan jumlah sampel 20 remaja putri di Panti Asuhan Darul Ulum Yogyakarta. Teknik analisa data menggunakan uji paired t-test, pengumpulan data dengan lembar observasi berupa Numeric Rating Scale. Hasil penelitian menunjukkan bahwa rata - rata intensitas dismenorea sebelum dilakukan intervensi 6,15 sedangkan setelah dilakukan intervensi 4,60. Hasil uji paired t-test didapatkan $\mathrm{p}$ value $0,000<0,05$. Terdapat pengaruh pemberian william's flexion exercise dan lantunan ayat suci Al Qur'an terhadap skala nyeri haid (dismenorea) di Panti Asuhan Darul Ulum Yogyakarta.
\end{abstract}

Kata kunci : Dismenorea, William's Flexion Exercise, Lantunan Ayat Suci Al Qur'an

\section{ABSTRACT}

Menstrual pain (dysmenorrhea) is pain that occurs before or during menstruation. Dysmenorrhea can interfere with adolescent activities and can indirectly interfere with their quality of life if left untreated. The objective of this study is to determine the effect of William's flexion exercise and the Qur'anic verses on the scale of menstrual pain (dysmenorrhea) in adolescent at the Darul Ulum Orphanage in Yogyakarta. This type of research uses a Pre-Experimental research design with one group pre-post test design. The 
sampling technique used purposive sampling with a sample of 20 young women at the Darul Ulum Orphanage in Yogyakarta. The data analysis technique used a paired t-test, collecting data with an observation sheet consisting of the Numeric Rating Scale. The results showed that the average intensity of dysmenorrhea before intervention was 6.15 while after intervention 4.60. The paired t-test results obtained p value 0,000<0,05. There was an influence of William's flexion exercise and the Qur'anic verses on the scale of menstrual pain (dysmenorrhea) at the Darul Ulum Orphanage in Yogyakarta.

Keywords: Dysmenorrhea, William's Flexion Exercise, The Qur'anic Verses.

\begin{tabular}{ll}
\hline Alamat Korespondensi & : Stikes Surya Global Yogyakarta \\
Email & astuti_dwi63@yahoo.co.id,dian.adkhana@gmail.com \\
\hline
\end{tabular}

\section{PENDAHULUAN}

Haid atau menstruasi adalah pengeluaran darah dan sel sel tubuh dari vagina yang berasal dari dinding rahim perempuan secara periodik. Rata-rata masa haid perempuan 3-8 hari dengan siklus rata-rata 28 hari pada setiap bulannya. (Erlina dalam Wagiyo, 2018). Selama berlangsungnya siklus haid (menstruasi), sebagian wanita akan timbul nyeri saat menstruasi yang biasanya disebut dismenorea.

Menuruut Laila dalam Pundati (2016), Dismenorea adalah sakit saat menstruasi yang dapat menyebabkan gangguan fisik seperti mual, lemas, dan diare dan dapat mengganggu aktivitas perempuan sehari - hari. Dismenorea berdasarkan penyebabnya dapat dibedakan menjadi dua yaitu: dismenorea sekunder dan dismenorea primer. Dismenorea sekunder adalah nyeri haid yang disebabkan oleh kelainan ginekologi (Wiknjosatro dalam Wagiyo, 2018), sedangkan dismenorea primer merupakan sebuah kondisi yang berhubungan dengan meningkatnya aktivitas uterus yang disebabkan karena meningkatnya produksi prostaglandin (Lowdermilk, 2012).

Angka kejadian nyeri menstruasi di dunia sangat besar, rata - rata lebih 50\% perempuan disetiap negara mengalami nyeri menstruasi (Nurwana, 2017). Kejadian menstruasi di Amerika Serikat diperkirakan hampir 90\% wanita mengalami nyeri haid (dismenorea), dan 10-15\% diantaranya mengalami nyeri haid (dismenorea) berat, yang menyebabkan mereka tidak mampu melakukan kegiatan apapun. Hasil survei di Indonesia angka kejadian dismenorea sebesar $64.25 \%$ yang terdiri dari $54,89 \%$ nyeri haid (dismenorea) primer dan 9,36\% nyeri haid (dismenorea) sekunder (Info sehat dalam Sumiyati, 2016). Angka kejadian dismenorea di Jawa Tengah mencapai 56\%. Hasil sensus Badan Pusat Statistik Propinsi Jawa Tengah Tahun 2010 menunjukkan jumlah remaja putri usia 10-19 tahun sebanyak 2.761.577 jiwa, sedangkan yang mengalami dismenorea di propinsi Jawa Tengah mencapai 1.518.867 jiwa atau 55\% (Badan Pusat Statistik Jawa Tengah, 2010).

Terjadinya dismenorea sangat mempengaruhi aktivitas bagi wanita khususnya remaja dalam kegiatan sehari - hari seperti tidak bisa konsentrasi sehingga proses dalam belajar menurun, dan tidak bisa beraktivitas. Gangguan menstruasi memerlukan perhatian khusus karena bila tidak ditangani dapat mempengaruhi kualitas hidup dan aktivitas sehari - hari (Locadives dalam Mundarti, 2017).

Metode penanganan dismenorea terdapat dua jenis terapi yang bisa dilakukan yaitu terapi farmakologi dan terapi non-farmakologi. Untuk menghilangkan rasa 
sakit yang disebabkan dismenorea dapat menggunakan terapi farmakologi dengan menggunakan obat - obat golongan analgetik untuk keluhan nyeri seperti aspirin, asam mefenamat, parasetamol, dan feminax. Dan menggunakan obat tradisional seperti air daun sirih, daun papaya, rimpang kunyit (Erlina dalam Wagiyo, 2018).

Upaya untuk mengatasi nyeri saat menstruasi dengan terapi non farmakologi yaitu dengan kompres menggunakan air hangat atau olahraga seperti jalan kaki dan peregangan otot. Salah satu contoh peregangan otot yang bisa dilakukan yaitu dengan William's Flexion Exercis. Beberapa gerakan William's Flexion Exercise bertujuan untuk menguatkan otot - otot abdominal dan memobilisasi lumbal bagian bawah. Kontraksi dari otot abdominal dan lumbal bagian bawah akan memberikan tekanan pada pembuluh darah besar di abdomen yang selanjutnya akan meningkatkan volume darah yang mengalir ke seluruh tubuh termasuk organ reproduksi. Hal tersebut dapat memperlancar supply oksigen ke pembuluh darah yang mengalami vasokontriksi, sehingga nyeri haid dapat berkurang (Laili dalam Oktaviani, 2017)

Menurut pandangan islam, anjuran untuk penanganan rasa sakit/rasa ketidaknyaman yang dialami adalah dengan membaca/ mendengarkan lantunan ayat suci Al Qur'an. Pelaksanaan membaca Al Qur'an dengan bacaan yang tartil itu akan mendatangkan ketenangan pada jiwa. Lantunan Al Qu'an secara fisik mengandung unsur suara manusia yang dapat mengaktifkan hormone endorphine alami, perasaan rileks mengalihkan perhatian dari rasa cemas dan tegang sehingga menurunkan tekanan darah serta memperlambat pernapasan, detak jantung dan aktivitas gelombang otak ( Sumaryani, 2015).

Pelaksanaan terapi William;s Flexion Exercise ini bisa di kolaborasikan dengan menggunakan alunan murratal dalam setiap gerakan terapi, sehingga dalam upaya penanganan yang dilakukan tidak hanya dengan terapi gerakan sesuai dengan ilmu yang berkembang tetapi juga dengan cara anjuran yang diperintahkan dalam ajaran islam (Sumaryani, 2015).

Berdasarkan studi pendahuluan yang dilakukan di Panti Asuhan Darul Ulum Yogyakarta, didapatkan hasil dari wawancara 20 remaja putri mengalami nyeri dismenorea dari tingkat sedang ke berat. Dari 20 remaja putri tersebut 8 diantaranya mengalami nyeri dismenorea berat yang mengganggu aktivitas sehari - hari dan tidak dapat mengikuti kegiatan pembelajaran disekolah, 7 remaja putri mengalami nyeri sedang dan 5 remaja putri mengalami nyeri ringan. Dari 20 remaja putri tersebut, 3 remaja putri melakukan kompres hangat pada saat nyeri haid, 5 remaja putri mengkonsumsi kunir asam dan 12 remaja putri tidak melakukan terapi farmakologi dan non-farmakologi pada saat mengalami nyeri haid (Dismenorea).

Tujuan pada penelitian ini adalah Untuk mengetahui pengaruh William's Flexion Exercise dan Lantunan Ayat Suci Al Qur'an terhadap Skala Nyeri Haid (Dismenorea) di Panti Asuhan Darul Ulum Yogyakarta

\section{METODE PENELITIAN}

Metode penelitian yang digunakan dalam penelitian ini adalah metode kuantitatif dengan desain penelitian pra-experimental dan rancangan One group pra-post test design. Tempat penelitian dan waktu penelitian dilakukan di Panti Asuhan Darul Ulum Yogyakarta 16 April - 25 Mei 2019. Populasi dalam penelitian ini adalah seluruh remaja putri komplek A Panti Asuhan Darul Ulum yang 
berjumlah 24 orang. Sampel dalam penelitian ini berjumlah 20 yang diambil dengan teknik Purposive Sampling.

Teknik analisis data yang digunakan dalam penelitian ini adalah analisis univariat yaitu karakteristik responden yang terdiri usia dan aktivitas belajar, sedangkan analisis bivariat menggunakan Uji Paired T-Test. Instrumen dalam penelitian ini menggunakan lembar observasi berupa Numeric Rating Scale.

Teknik pengumpulan data dalam penelitian ini menggunakan data primer dan data sekunder. Data primer didapatkan dengan teknik pengumpulan data menggunakan wawancara tentang identitas responden dan observasi skala nyeri haid (dismenorea) yang dirasakan responden dengan menggunakan skala nyeri Numeric Rating Scale, sedangkan untuk data sekunder didapatkan melalui pengasuh Panti Asuhan Darul Ulum dengan teknik wawancara berupa jumlah data responden.

\section{HASIL}

\section{HASIL DAN PEMBAHASAN}

1. Karakteristik Responden

a. Usia Responden

Tabel 4.1 Distribusi Frekuensi Usia Responden pada Remaja Putri Di Panti Asuhan Darul Ulum Yogyakarta Tahun 2019

Tabel 4.1

Distribusi Frekuensi Usia Responden pada Remaja Putri Di Panti Asuhan Darul Ulum Yogyakarta

Tahun 2019

\begin{tabular}{llll}
\hline No & Usia & Frekuensi & Presentase $(\mathbf{\%})$ \\
\hline $\mathbf{1}$ & 14 Tahun & 2 & \multicolumn{2}{c}{10.0} \\
\hline $\mathbf{2}$ & 15 Tahun & 4 & 20.0 \\
\hline $\mathbf{3}$ & 16 Tahun & 7 & 35.0 \\
\hline $\mathbf{4}$ & 17 Tahun & 2 & 10.0 \\
$\mathbf{5}$ & 18 Tahun & 5 & 25.0 \\
\hline & Jumlah & 20 & 100.0 \\
\hline
\end{tabular}

Sumber : Data Primer 2019

Berdasarkan data dari tabel 4.1 diatas menunjukkan karakteristik responden berdasarkan usia responden. Responden terbanyak adalah remaja putri yang berusia 16 tahun yaitu sebanyak 7 orang (35\%). Responden paling sedikit berusia 14 dan 17 tahun yaitu sebanyak 2 orang (10\%).

b. Kategori Aktivitas Belajar

Tabel 4.2 Kategori Aktivitas Belajar Remaja Putri Panti Asuhan Darul Ulum Yogyakarta 2019. 
Tabel 4.2

Kategori Aktivitas Belajar Remaja Putri

Panti Asuhan Darul Ulum Yogyakarta 2019.

\begin{tabular}{|c|c|c|c|c|c|c|}
\hline \multirow{3}{*}{$\begin{array}{l}\text { Kejadian } \\
\text { Nyeri Haid } \\
\text { (Dismenorea) }\end{array}$} & \multicolumn{4}{|c|}{ Aktivitas Belajar } & \multirow{2}{*}{\multicolumn{2}{|c|}{ Total }} \\
\hline & \multicolumn{2}{|c|}{$\begin{array}{l}\text { Tidak } \\
\text { Terganggu }\end{array}$} & \multicolumn{2}{|c|}{ Terganggu } & & \\
\hline & $\mathrm{N}$ & $\%$ & $\mathrm{~N}$ & $\%$ & $\mathrm{~N}$ & $\%$ \\
\hline $\begin{array}{l}\text { Nyeri Haid } \\
\text { (Dismenorea) }\end{array}$ & 7 & 35 & 13 & 65 & 20 & 100 \\
\hline Total & & & & & 20 & 100 \\
\hline
\end{tabular}

Sumber : Data Primer, 2019

Berdasarkan data dari tabel 4.2 diatas menunjukkan kategori aktivitas belajar remaja putri selama mengalami nyeri haid (Dismenorea). Aktivitas belajar dibagi menjadi 2 yaitu tidak terganggu dan terganggu. Dari 20 responden remaja putri 13 responden ( 65\%) menyatakan aktivitas belajar terganggu dan 7 responden (35\%) tidak terganggu untuk aktivitas belajarnya.

2. Analisis Univariat

a. Skala Nyeri Haid Responden

Deskripsi Data Skala Nyeri Dismenorea Pada Remaja Putri Di Panti Asuhan Darul Ulum Yogyakarta Pada Kelompok Eksperimen..

Tabel 4.3

Distribusi Data Skala Nyeri Dismenorea Pada Remaja Putri Di Panti Asuhan Darul Ulum Yogyakarta Tahun 2019

\begin{tabular}{llllll}
\hline \multirow{2}{*}{ NO } & \multirow{2}{*}{$\begin{array}{l}\text { Skala } \\
\text { Dismenorea }\end{array}$} & Nyeri & \multicolumn{4}{l}{ Kelompok Eksperimen } \\
\cline { 3 - 6 } & & Pre Test & \multicolumn{3}{l}{ Post Test } \\
\cline { 3 - 6 } & F & $\%$ & F & $\%$ \\
\hline 1 & Tidak Nyeri & 0 & 0 & 0 & 0 \\
\hline 2 & Nyeri Ringan & 4 & 20 & 7 & 35 \\
\hline 3 & Nyeri Sedang & 6 & 30 & 8 & 40 \\
\hline 4 & Nyeri Berat & 10 & 50 & 5 & 25 \\
\hline \multicolumn{2}{l}{ Total } & 20 & 100 & 20 & 100 \\
\hline
\end{tabular}

Sumber : Data Hasil Pengolahan

Berdasarkan data pada tabel diatas menunjukkan bahwa pada saat pre test pada kelompok eksperimen skala nyeri dalam kategori nyeri ringan sebanyak 4 orang (20\%), kemudian pada saat post test mengalami kenaikan menjadi 7 orang $(35 \%)$. Sedangkan untuk kategori nyeri sedang pada saat pre test sebanyak 6 orang $(30 \%)$, kemudian pada post test mengalami kenaikan sebanyak 8 orang $(40 \%)$. Kategori nyeri berat pada saat pre test berjumlah 10 orang $(50 \%)$, kemudian turun menjadi 5 orang $(25 \%)$ pada saat post test. Berdasarkan data diatas tidak ada remaja putri yang tidak 
merasakan nyeri pada saat siklus haid berlangsung sehingga frekuensinya berjumlah nol.

3. Analisis Bivariat

a. Uji Normalitas

Penelitian ini menggunakan uji normalitas Saphiro Wilk.

Tabel 4.4

Uji Normalitas data menggunakan uji Saphiro Wilk

\begin{tabular}{llll}
\hline Shapiro Wilk & & & \\
\hline & Statistic & df & Sig. \\
\hline Pre-test & .934 & 20 & .183 \\
\hline Post-test & .944 & 20 & .299 \\
\hline
\end{tabular}

Sumber : Data Pengolahan

Berdasarkan uji normalitas diatas, nilai signifikasi pre test sebesar 0,183> 0,05 , sehingga dapat disimpulkan sebaran data untuk pre test berdistribusi normal. Sedangkan nilai signifikasi post test sebesar $0,290>0,05$, sehingga dapat disimpulkan sebaran data untuk post test berdistribusi normal. Berdasarkan hasil nilai signifikasi tersebut dapat dilanjutkan uji statistik $\mathrm{t}$ test.

b. Hasil Uji Paired T-Test Pada Kelompok Eksperimen.

Untuk mengetahui hasil perhitungan uji perbedaan skala nyeri Dismenorea pada pre test dan post test dapat dilihat pada tabel 4.5.

Tabel 4.6

Hasil Uji Paired t-test

Pada Kelompok Eksperimen

\begin{tabular}{|c|c|c|c|c|}
\hline Data & Mean & $\mathbf{N}$ & t-hitung & $\begin{array}{l}\text { Sig.(2- } \\
\text { tailed) }\end{array}$ \\
\hline Pre-test & 6,15 & 20 & 13,581 & 0,000 \\
\hline Post-test & 4,60 & 20 & & \\
\hline
\end{tabular}

Sumber : Data Primer, 2019

Hasil uji analisis menggunakan Paired t-test didapatkan data bahwa nilai signifikan 2-tailed (p) skala nyeri haid (Dismenorea) sebelum (pre-test) dan sesudah (post-test) dilakukannya pemberian terapi William's Flexion Exercise dan Lantunan Ayat Suci Al-Qur'an sebesar 0,000 dengan $\alpha=0,05$, dimana nilai tersebut $(\mathrm{p}<0,05)$ maka Ho ditolak dan Ha diterima, artinya ada pengaruh pemberian terapi William's Flexion Exercise dan Lantunan ayat suci Al-qur'an terhadap skala nyeri Dismenorea remaja putri di Panti Asuhan Darul Ulum Yogyakarta.

\section{PEMBAHASAN}

1. Nyeri Dismenorea sebelum dan sesudah diberikan William's Flexion Exercise dan Lantunan Ayat Suci Al Qur'an Pada Remaja Putri. 
Menstruasi merupakan pertanda masa reproduktif pada kehidupan seorang wanita. Siklus ini akan berlangsung secara periodik. Selama berlangsungya siklus haid ( menstruasi) sebagian wanita akan merasakan nyeri haid (Dismenorea) (Rudi dalam Wagiyo, 2018). Dismenorea sendiri menurut penyebabnya dibagi menjadi 2 yaitu Dismenorea Primer dan Dismenorea Sekunder. Nyeri Haid ( Dismenorea) yang biasa dialami oleh sebagian besar wanita khususnya remaja adalah Dismenorea Primer. Hasil penelitian dari tabel 4.4 dapat dilihat skala nyeri responden sebelum diberikan terapi William's Flexion Exercise dan Lantunan Ayat Suci Al Qur'an. Penelitian ini dilakukan pada 20 remaja putri di Panti Asuhan Darul Ulum Yogyakarta, dimana hasil pengukuran nyeri haid (Dismenorea) sebelum perlakuan (pre-test) dapat dilihat dari keseluruhan responden mayoritas mengalami nyeri haid (Dismenorea) dalam skala nyeri sedang yaitu sebanyak 6 responden (30\%) dan nyeri berat yaitu sebanyak 10 responden (50). Distribusi untuk responden yang mengalami skala nyeri ringan hanya sedikit yaitu 4 responden $(20 \%)$.

Hasil pengukuran nyeri haid (Dismenorea) sesudah perlakuan (posttest) adalah nyeri ringan sebanyak 7 orang $(35 \%)$, responden dengan nyeri sedang sebanyak 8 orang $(40 \%)$, sedangkan responden yang mengalami skala nyeri berat mengalami penurunan dari 10 orang $(50 \%)$ menjadi 5 orang $(25 \%)$. Hasil tersebut dapat dilihat dari lembar observasi yang telah diisi responden dengan cara melingkari nilai skala nyeri dari 0 sampai dengan 10 sesuai dengan nyeri yang dirasakan.

Seorang remaja yang mengalami nyeri haid ( Dismenorea) akan mengalami gangguan dalam aktivitas belajarnya. Belajar merupakan aktivitas yang melibatkan kerja fisik dan juga kerja otak. Terganggunya aktivitas belajar pada remaja akibat nyeri haid (Dismenorea) dapat meningkatkan frekuensi ketidakhadiran dalam proses pembelajaran di sekolah (Ningsih, 2011 dalam Pundati, 2015). Hasil penelitian dalam tabel 4.2 menunjukkan dari 20 responden 13 remaja putri $(65 \%)$ mengalami aktivitas belajar yang terganggu dan 7 remaja putri (35\%) tidak terganggu dalam aktivitas belajarnya akibat nyeri haid (Dismenorea).

Penelitian Putri et all, 2017, menunjukkan bahwa terdapat hubungan yang signifikan antara nyeri haid (Dismenorea) dengan aktivitas belajar, artinya semakin tinggi skala nyeri haid (Dismenorea) yang dirasakan oleh siswi maka semakin tinggi aktivitas belajar yang terganggu. Nyeri haid (Dismenorea) yang dirasakan oleh siswi akan berdampak baik dari segi fisik dan segi psikologis. Siswi akan merasakan cepat letih, tidak bersemangat, dan sulit untuk berkonsentrasi dalam proses pembelajaran karena rasa tidak nyaman yang dirasakan ketika haid (menstruasi).

Nyeri Haid (Dismenorea) timbul karena beberapa faktor. Menurut Laksmi et all (2011) dalam Pundati menyebutkan bahwa salah satu faktor yang berhubungan dengan kejadian dismenorea adalah usia. Nyeri Haid sering terjadi pada wanita usia muda. Hal tersebut dikarenakan wanita usia muda alat reproduksi belum siap mengalami perubahan - perubahan dan belum berfungsi secara optimal. Perempuan semakin tua lebih sering mengalami menstruasi dan sudah mengalami proses melahirkan maka leher rahim akan bertambah lembar sehingga pada usia tua kejadian dismenorea jarang ditemukan ( Wirawan dalam Rahayu, 2017).

Hasil penelitian dari tabel 4.1 dapat diketahui bahwa remaja putri terbanyak mengalami nyeri haid (Dismenorea) adalah remaja dengan usia 16-18 
tahun yaitu sebanyak 14 orang (70\%). Hasil penlitian itu sejalan dengan penelitian Suliawati dalam Rahayu (2017) mendapatkan hasil dimana usia 1usia 16-25 mengalami dismenorea terbanyak sebesar 35,0\%.

Menurut Neinsten dalam Pustikawati (2016) nyeri haid dismenorea dapat terjadi 1-3 tahun setelah seseorang mengalami menstruasi pertama dan mencapai maksimalnya pada usia 15-25 tahun. Hal tersebut dikarenaka pada awal menstruasi siklusnya masih anovulasi sehinnga banyak remaja yang tidak mengalami dismenorea di awal menstruasi.

Keluhan yang sering muncul pada saat dismenorea selain nyeri di perut adalah nyeri dibagian punggung dan panggul. Hal ini terjadi karena pada saat dismenorea terjadi kontraksi pada rahim sehinngga otot - otot dibagian perut dan punggung menegang. Gerakan dalam terapi William's Flexion Exercise ini selain dapat mengulur otot dibagian perut perut juga dapat mengulur otot dibagian punggung. Teori tersebut sejalan dengan penelitian Angga (2014), mendapatkan hasil bahwa William's Flexion Exercise berpengaruh terhadap intensitas nyeri punggung belakang karena terjadi penurunan ketegangan otot bagian lumbo sacral spinal.

Metode penanganan dismenorea terdapat dua jenis terapi yaitu terapi farmakologi dan terapi non-farmakologi. Salah satu upaya untuk penangan dismenorea secara non-farmakologi yaitu dengan cara olahraga peregangan otot. Peregangan otot yang di sarankan adalah peregangan otot pada bagian perut dan bagian panggul. Dengan melakukan peregangan otot diharapkan otot - otot akan melemas dan rileks, sehingga nyeri haid (Dismenorea) akan berkurang (Andira dalam Wagiyo,2018). Metode yang digunakan dalam penelitian ini yaitu pemberian terapi William's Flexion Exercise yang di kombinasikan dengan Lantunan Ayat Suci Al Qur'an.

Skala nyeri dismenorea setelah diberikan terapi William's Flexion Exercise dengan Lantunan Ayat Suci Al Qur'an menunjukkan bahwa terjadi peningkatan jumlah pada nyeri ringan dan nyeri sedang, sedangkan pada nyeri berat ada penurunan skala nyeri setelah pemberian William's Flexion Exercise dengan Lantunan Ayat Suci Al Qur'an. Hal ini menunjukkan terapi William's Flexion Exercise dengan Lantunan Ayat Suci Al Qur'an efektif untuk meringankan nyeri dismenorea pada responden. Hasil penelitian tersebut sejalan dengan penelitian Lestari, (2017), menunjukkan bahwa terjadi peningkatan frekuensi skala nyeri ringan dan sedang pada mahasiswi setelah melakukan William's Flexion Exercise masing - masing sebanyak 6 mahasiswi $(23,7 \%)$ untuk nyeri ringan, sebanyak 3 mahasiswi (11.5\%) untuk nyeri sedang. Sedangkan pada kelompok yang mengalami nyeri berat terjadi penurunan yang sangat signifikan secara angka yaitu sebanyak 9 mahasiswi (34.6\%).

Menurut Hill dalam Lestari (2017), Latihan William's Flexion Exercise adalah suatu latihan dengan tujuan untuk mengulur otot - otot bagian posterior dan juga meningkatkan kekuatan otot abdominal. Disamping itu William's Flexion Exercise dapat meningkatkan tekanan intra abdomen yang mendorong kolumna vertebralis ke arah belakang, dengan demikian akan membantu mengurangi hiperlordosis lumbal dan mengurangi tekanan pada diskus intervertebralis. Sehingga sangat efektif dalam mengurangi nyeri haid (Dismenorea) karena dapat merenggangkan otot pada daerah perut dan punggung. 
Penelitian Harsiwi, (2014), menunjukkan bahwa setelah diberikan pemberian alunan murrotal pada 15 responden terjadi penurunan nyeri Dismenorea, sebanyak $75 \%$ merasakan nyeri ringan dan $25 \%$ mengalami nyeri sedang. Pelaksanaan mendengarkan lantuna ayat suci Al Qur'an akan mendatangkan ketenangan jiwa karena dapat mengaktifkan hormone endorphine alami, perasaan rileks yang dapat mengalihkan perhatian dari rasa cemas dan tegang. Pada saat seseorang melakukan relaksasi dengan baik dan didukung dengan lingkungan yang tenang maka hal tersebut akan memberikan efek terhadap penurunan skala nyeri haid (Dismenorea) yang dirasakan.

2. Pengaruh Terapi William's Flexion Exercise Dengan Lantunan Ayat Suci Al Qur'an Terhadap Skala Nyeri Haid (Dismenorea) Pada Remaja Putri di Panti Asuhan Darul Ulum Yogyakarta.

Berdasarkan analisis bivariat mendapatkan hasil statistik Sig.t $=0,000$ $<0,05$ menunjukkan adanya pengaruh yang bermakna, artinya ada pengaruh yang signifikan antara terapi William's Flexion Exercise dengan Lantunan Ayat Suci Al Qur'an terhadap Skala Nyeri Haid pada Remaja Putri di Panti Asuhan Darul Ulum Yogyakarta.

Berdasarkan hasil analisis dengan menggunakan uji Paired T-Test dengan menggunakan SPSS 16,0 For Windows dengan taraf signifikasi 5\% didapatkan nilai $t$ hitung tingkat nyeri haid (Dismenorea) sebelum diberikan dan sesudah diberikan perlakuan sebesar 13,581 dan nilai t tabel sebesar 2,093 (t hitung $>\mathrm{t}$ tabel) dengan nilai signifikasi $\mathrm{P}$ sebesar 0,000 dimana nilai tersebut $(\mathrm{P}<0,05)$ maka dapat disimpulkan Ho ditolak dan Ha diterima, artinya ada pengaruh pemberian terapi William's Flexion Exercise dan Lantunan ayat suci Al-qur'an terhadap nyeri Dismenorea remaja putri di Panti Asuhan Darul Ulum Yogyakarta. Perbedaan rata - rata (mean) tingkat nyeri haid (Dismenorea) pre-test dan posttest.

Penelitian tersebut sejalan dengan penelitian yang dilakukan Oktaviani dan Lestari (2017) yang meneliti tentang “Efektivitas William's Flexion Exercise Dalam Pengurangan Nyeri Haid (Dismenorea)". Hasil uji statistik dengan menggunakan Wilcoxon Mathched Pairs didapatkan hasil nilai Z hitung - 3,638 ternyata lebih besar dari 1,96 sehingga William's Flexion Exercise efektif dalam pengurangan nyeri haid (Dismenorea) dimana dari 26 responden mengalami penurunan nyeri skala nyeri secara signifikan.

Menurut Laili dalam Oktaviani (2017), beberapa gerakan William's Flexion Exercise bertujuan untuk menguatkan otot - otot abdominal dan memobilisasi lumbal bagian bawah. Kontraksi otot abdominal dan lumbal bagian bawah akan memberikan tekanan pada pembuluh darah besar sehingga dapat memperlancar supply oksigen ke pembuluh darah yang mengalami vasokontriksi, sehingga nyeri haid dapat berkurang. Pentingnya otot dinding abdomen yang dinyatakan oleh Sweet dalam Lestari (2017) yaitu berfungsi sebagai stability posture dan meningkatkan tekanan intra abdomen yang digunakan untuk defleksi, pengeluaran urin, peningkatan his pada proses persalinan dan kekuatan ekshlasi.

Sejalan dengan penelitian Sumaryani dan Praditiana (2015) mendapatkan hasil senam dismenorea berbasis Ar-Rahman secara statistik terbukti lebih efektif dalam menurunkan nyeri menstruasi dibandingkan dengan interval yang lain yang hanya dilakukan senam dismenorea saja dan murrotal saja, dengan 
$p=0,01$. Rerata pre interval sebesar 31.31 sedangkan rerata post intervensi sebesar 19,50. Terapi kombinasi antara senam dan mendengarkan murrotal Al Qur'an Surah Ar-Rahman mempunyai beberapa keunggulan dan mampu memberikan efek ganda dalam menurunkan nyeri.

Olahraga atau senam merupakan salah satu teknik relaksasi yang dapat digunakan untuk mengurangi nyeri haid (dismenorea). Senam yang dilakukan teratur selama 10-30 menit akan menyebabkan otot - otot panggul dan otot - otot uterus akan mengalami relaksasi. Jenis senam yang dapat dilakukan salah satunya adalah William's Flexion Exercise. Senam dapat memberikan efek relaksasi karena gerakan - gerakan senam dapat membantu melancarkan peredaran darah yang berada disekitar rahim, mengurangi produksi prostaglandin dan mengurangi vasokontriksi pembuluh darah sehingga dapat meminimalkan kontraksi uterus (Anugroho dalam Sumaryani, 2015)

Terapi murrotal mempunyai efek yang sangat diperlukan dalam mengatasi kecemasan dan membentuk gaya koping yang positif karena murrotal Al Qur'an Surah Ar Rahman mampu memberikan stimulant untuk memunculkan gelombang delta yag berfungsi membuat pikiran menjadi tenang dan nyaman sehingga responden sampai bisa tertidur karena alunan murrotal tersebut dan dapat menurunkan tingkat nyeri Dismenorea.

Menurut zahro dalam Sumaryani (2015) Surah Ar Rahman menceritakan tentang luasnya rahmat Allah. Allah telah meciptakan manusia dalam bentuk yang sebaik - baiknya, menceritakan tentang keseimbangan dan memuat unsur- unsur pendidikan. Surah Ar-Rahman dimaknai sebagai surah yang menjelaskan pentingnya bersyukur karena karunia Allah SWT yang sangat luas, termasuk mensyukuri semua kondisi. Sakit ataupun Dismenorea juga dimaknai sebagai karunia Allah SWT, sehingga orang yang memaknai kesehatan jasmani, rohani dan akal.

Sejalan dengan penelitian Alfiana (2014), menunjukkan bahwa rata rata intensitas Dismenorea sebelum diberikan intervensi 5,40 sedangkan sesudah intervensi 2,90. Terdapat perbedaan rata -rata sebelum dan sesudah intervensi. Sehingga terdapat pengaruh pemberian alunan murrotal dan aromaterapi lavender terhadap intensitas Dismenorea pada mahasiswi.

Pemberian distraksi menggunakan alunan murrotal telah berhasil dilakukan untuk menurunkan Dismenorea. Hal ini didukung oleh penelitian Prastiwi dan Listyaningrum (2017), bahwa terapi murrotal dapat menurunkan intensitas nyeri yang dirasakan. Terapi murrotal memiliki pengaruh yang signifikan terhadap Dismenorea yaitu dapat menurunkan nyeri pada 15 orang responden dari derajat sedang menjadi ringan. Selisih rata - rata sebelum dan sesudah diberikan murrotal adalah 2,00. Hal tersebut dapat disimpulkan terjadi penurunan jumlah rata - rata setelah diberikan terapi murrotal.

Latihan fisik (exercise) sangat dianjurkan dilakukan dalam upaya pencegahan nyeri haid (dismenorea) karena latihan fisik dapat menghasilkan hormone endorphin yang berfungsi sebagai obat penenang alami yang di produksi otak sehinngga menimbulkan rasa nyaman dan dapat mendistraksi perhatian dari rasa nyeri. Latihan fisik juga dapat mengurangi gejala sindrom pramenstruasi (PMS) dengan cara serupa.

Dari hasil penelitian ternyata dismenorea lebih sedikit terjadi pada olahragawati dibadningkan wanita yang tidak melakukan olahrga/exercise 
(Andrews dalam Salbiah, 2012). William's Flexion Exercise adalah salah satu bentuk latihan fisik yang dapat dilakukan dalam upaya pencegahan nyeri haid (Dismenorea). Melakukan William's Flexion Exercise teratur setiap hari mendekati siklus menstruasi selama 10 menit dapat mencegah terjadinya nyeri haid (dismenorea) (Oktaviani, 2017).

\section{KESIMPULAN}

Berdasarkan hail penelitian tentang pengaruh William's Flexion Exercise dengan lantunan ayat suci Al Qur'an terhadap skala nyeri haid (dismenorea) pada remaja putri di Panti Asuhan Darul Ulum Yogyakarta dapat ditarik kesimpulan sebagai berikut:

a. Tingkat nyeri kelompok eksperimen pada saat pre-test dalam kategori ringan sebanyak 4 orang (20\%), kategori nyeri sedang sebanyak 6 orang $(30 \%)$ dan kategori nyeri berat sebanyak 10 orang (50\%), sedangkan tingkat nyeri kelopok ekspreimen pada saat post-test yaitu dalam kategori nyeri ringan sebanyak 7 orang (35\%), kategori nyeri sedang yaitu sebanyak 8 orang $(40 \%)$, dan kategori nyeri berat yaitu 5 orang $(25 \%)$.

b. Setelah dilakukan pemberian terapi William's Flexion Exercise dengan Lantunan Ayat Suci Al Qur'an, nyeri dalam kategori ringan mengalami kenaikan yaitu dari 4 orang $(20 \%)$ menjadi 7 orang $(35 \%)$, kategori nyeri ringan mengalami kenaikan yaitu dari 6 orang (30\%) menjadi 8 orang (40\%), sedangkan dalam kategori nyeri berat mengalami penurunan yaitu dari 10 orang $(50 \%)$ menjadi 5 orang $(25 \%)$.

c. Ada pengaruh yang signifikan antara terapi William's Flexion Exercise dengan Lantunan Ayat Suci Al Qur'an terhadap Skala Nyeri Haid pada Remaja Putri di Panti Asuhan Darul Ulum Yogyakarta. Hal ini ditunjukkan dengan nilai t hitung lebih besar dari nilai t tabel yaitu 13,581>2,093 atau nilai $\mathrm{p}=0,000(\mathrm{p}<0,05)$. Rata- rata untuk pre-test sebesar 6,5 dan untuk rata - rata post test sebesar 4,60.Perbedaan rata - rata (mean) skala nyeri haid (dismenorea)pre dan post test sebesar 1,55.

\section{DAFTAR PUSTAKA}

Angga, dkk. 2014. Pengaruh Terapi William's Flexion Exercise Terhadap Nyeri Punggung Bawah Pada Lansia Di Panti Werdha

Badan Pusat Statistik Jawa Tengah. 2010. Data Statistik Jawa Tengah, Jawa Tengah.

Dahlan, Muhamad Sopiyudin.2014. Statistik Untuk Kedokteran dan Kesehatan.Jakarta : Epidemiologi Indonesia.

Harsiwi. 2014. Pengaruh Alunan Murrotal terhadap Intensitas Nyeri Dismenorea Primer pada Siswi Madrasah Mua'limaat Muhamadiyah Yogyakarta. Skripsi, Universitas Muhamadiyah Yogyakarta.

Lowdermilk, dkk. 2013. Keperawatan Maternitas Edisi 8. Jakarta : Salemba Medika.

Mundarti, dkk. 2017. Pengaruh Abdominal Stretching Exercise Terhadap Intensitas Nyeri Dismenorea. Jurnal Kebidanan Vol 6 No 12, April 2017.

Nursalam. 2015. Metodologi Penelitian Ilmu Keperawatan. Jakarta : Salemba Medika. 
Nurwana, dkk. 2017. Analisis Faktor yang Berhubungan Dengan Kejadian Dismenorea pada Remaja Putri Di SMA Negeri 8 Kendari Tahun 2015. Jurnal Ilmiah Mahasiswa Kesehatan Masyarakat Vol 2 No 1, Mei 2017.

Notoadmojo, S. 2012. Metodologi Penelitian Kesehatan. Jakarta : Rineka Cipta.

Oktaviani, A\& Lestari, U. 2017. Efektivitas William's Flexion Exercise Dalam Pengurangan Nyeri Haid Dismenorea. Jurnal Ilmiah Kebidanan, Volume 8 No 1, Edisi Juni 2017.

Putri, dkk. 2017. Hubungan Antara Nyeri Haid (Dismenorea) Terhadap Aktivitas Belajar Pada Siswi Kelas XI SMA NEGERI 52 JAKARTA. Jurnal Ilmu Keolahragaan : Universitas Negeri Malang.

Prastiwi, W \& Listyaningrum.2017. Pengaruh Alunan Murrotal Tehadap Intensitas Nyeri Dismenorea Primer Pada Siswi Aliyah di Pondok Pesantren As-Salafiah Mlangi Yogyakarta. Jurnal Universitas Aisyah Yogyakarta.

Pundati, dkk. 2015. Faktor - Faktor yang Berhubungan Dengan Kejadian Dismenorea pada Mahasiswa Semester VIII Universitas Jenderal Soedirman Purowkerto. Jurnal Kesmas Indonesia, Volume 8 No 1, Januari 2016.

Rahayu, dkk. 2017. Pengaruh Endorphine Massage Terhadap Rasa Sakit Dismenorea Pada Mahasiswi. Jurnal Kebidanan Poltekkes Kemenkes Tasikmalaya Tahun 2017. Jurnal Bidan “ Midwife Journal” Volume 3 No 2, Juli 2017.

Salbiah. 2012. Penurunan Tingkat Nyeri Saat Menstruasi Melalui Latihan Abdominal Stretching. Jurnal Ilmu Keperawatan : Universitas Syiah Kuala Banda Aceh.

Sugiyono. 2012. Metode Penelitian Kuantitatif Kualitatif dan R\&D. Bandung : Alfabeta

Sumaryani, dkk. 2015. Senam Dismenorea Ar-Rahman Terhadap Penurunan Nyeri. Jurnal Ners Vol 10.No 2, Oktober 2015.

Wagiyo \& Rahmawati. 2018. Pengaruh Pemberian Abdominal Stretching Exercise Terhadap Tingkat Nyeri Dismenorea Pada Siswi Di SMP N 30 Semarang. Jurnal Ilmiah Keperawatan, Maret 2018. 